\title{
Quantification of the Serotonin IA Receptor Using PET: Identification of a Potential Biomarker of Major Depression in Males
}

\author{
Joshua Kaufman', Gregory M Sullivan ${ }^{2}$, Jie Yang', R Todd Ogden ${ }^{3}$, Jeffrey M Miller ${ }^{2}$, Maria A Oquendo ${ }^{2}$, \\ J John Mann², Ramin V Parsey' and Christine DeLorenzo*, I \\ 'Stony Brook University, Stony Brook, NY, USA; '2Columbia University College of Physicians and Surgeons, New York City, NY, USA; \\ ${ }^{3}$ Columbia University School of Public Health, New York City, NY, USA
}

\begin{abstract}
Multiple lines of research have implicated the serotonin IA (5-HT IA) receptor in major depressive disorder (MDD). Despite this, quantification of $5-\mathrm{HT}_{\mathrm{IA}}$ is yet to yield a clinically relevant MDD biomarker. One reason may be that reported sex differences in the serotonergic system confound the comparison between diagnostic groups. Therefore, this study sought to determine whether differences in 5-HTIA binding between depressed and control subjects are affected by sex. Using positron emission tomography (PET), serotonin IA binding was quantified in 50 patients with MDD (34 female, 16 male) and 57 healthy controls (32 female, 25 male). The subjects' 5-HT IA density ( $\mathrm{BP}_{\mathrm{F}}$, equal to the product of the density of available receptors and tracer affinity), was determined by using the PET tracer [carbonyl-C-I I]-WAY-I00635, a selective 5-HT IA antagonist. Results indicated that male MDD subjects had a 67.0\% higher $\mathrm{BP}_{\mathrm{F}}$ across 13 brain regions compared with male controls $(\mathrm{df}=103, p<0.000 \mathrm{I})$. The greatest difference between MDD subjects and controls was in the raphe $(132 \%, p=0.000)$. Furthermore, by using a threshold, male controls can be distinguished from depressed males with high sensitivity and specificity (both $>80 \%$ ). In females, the separation between diagnostic groups yields much lower sensitivity and specificity. This data therefore suggests a specific biosignature for MDD in males. Identification of such a biosignature could provide a deeper understanding of depression pathology, help identify those at highest risk, and aid in the development of new therapies. Further, these findings suggest that combining male and female cohorts may not be optimal for some MDD studies.
\end{abstract}

Neuropsychopharmacology (2015) 40, 1692-1699; doi:I0.1038/npp.20I5.I5; published online II February 2015

\section{INTRODUCTION}

Major depressive disorder (MDD) is associated with a high degree of morbidity and mortality (Merikangas et al, 2007), and is predicted to be the leading cause of disease burden by the year 2030 (World Health Orangization, 2004). Currently, in the United States alone, 30-45 million patients suffer from depression-related disorders. Moreover, MDD is the leading cause of disability for people aging 15-44 (Palucha and Pilc, 2007; World Health Organization et al, 2004) and will affect up to $16.2 \%$ of Americans at some point in their lifetime (Kessler et al, 2003). Further compounding the challenge of MDD, the largest clinical trial of MDD treatments ever conducted, $\operatorname{STAR}^{\star} \mathrm{D}$, indicated that two-third of MDD patients do not achieve remission (ie, the absence of depressive symptoms) from the first antidepressant they are prescribed (Hierholzer, 2006). Our

*Correspondence: Dr C DeLorenzo, Department of Psychiatry, Biomedical Engineering, Stony Brook University, HSC-T-10, Room 40D, Stony Brook, NY 11794, USA, Tel: +I 63I 638 I523, Fax: + 631444 1560,

E-mail: christine.delorenzo@stonybrookmedicine.edu

Received 23 July 2014; revised 13 November 2014; accepted 9 December 2014; accepted article preview 8 January 2015 infectiveness in treating this disease is a direct consequence of our lack of understanding of depression pathophysiology. Therefore, in order to treat this prevalent disorder, a deeper understanding of its biology is required (Insel, 2009).

Previous research has implicated the serotonergic system in MDD pathophysiology (Boldrini et al, 2008; Parsey et al, 2006; Sargent et al, 2000; Savitz et al, 2009; Stockmeier, 2003) and selective serotonin reuptake inhibitors remain a first-line treatment, further implicating serotonergic dysfunction in MDD (Blier et al, 1998; Parsey et al, 2010; Sullivan et al, 2009). Given its key role in MDD, the serotonergic system is a natural substrate in which to search for a biomarker (a characteristic that can be objectively measured and used as an indicator of either normal or pathogenic processes (Singh and Rose, 2009)) of depression. Uncovering such a biomarker could improve early diagnosis, treatment planning, and monitoring, and the search for novel therapeutics.

A confounding factor that may have inhibited the identification of such a biomarker from the serotonergic system thus far is the sex difference. As early as 1970, it was shown that central serotonin levels as well as cerebrospinal fluid (CSF) concentrations of the serotonin metabolite 
5-hydroxyindole-3-acetic acid (5-HIAA) were higher in female than male rats (Rosecrans, 1970). Further, animal literature has shown that $5-\mathrm{HT}_{1 \mathrm{~A}}$ binding is modulated by estrogen levels in females (Flugge et al, 1999; PecinsThompson and Bethea, 1999; Zhang et al, 1999) and that downregulation of $5-\mathrm{HT}_{1 \mathrm{~A}}$ autoreceptors in the dorsal raphe nucleus is induced by female sex hormones (Birzniece $e t$ al, 2001; Maswood et al., 1995; Pecins-Thompson and Bethea, 1999). Conversely, rat studies have shown that estrogen induces up-regulation of $5-\mathrm{HT}_{1 \mathrm{~A}}$ receptors in forebrain regions such as the medial preoptic area (Frankfurt et al, 1994). Further, along with female sex hormones, androgens such as testosterone are able to increase the firing activity of 5-HT neurons in both male and female rats (Robichaud and Debonnel, 2005). Consistent with the animal studies, in humans, the mean rate of serotonin synthesis in males has been estimated to be $52 \%$ higher than in females (Nishizawa et al, 1997). Post-mortem human and studies of CSF have also revealed the sex differences in serotonin metabolite 5hydroxyindole-3-acetic acid (5-HIAA) levels (Gottfries et al, 1974)(Arango et al, 2001).

Positron emission tomography (PET) allow the visualization and quantification of the serotonergic system. Consistent with post-mortem and preclinical studies, human PET studies examining the serotonin $1 \mathrm{~A}, 2 \mathrm{~A}, 1 \mathrm{~B}$, or transporter in vivo, mostly provide support of serotonergic dysfunction in MDD (Savitz and Drevets, 2013). Such studies performed by our group using radioligand $\mathrm{N}-(2-(4-$ (2-methoxyphenyl)-1-piperazinyl)ethyl)-N-(2-pyridinyl)cyclo-hexanecarboxamide ([carbonyl-C-11]-WAY-100635 or $\left[{ }^{11} \mathrm{C}\right]$ WAY100635), a selective $5-\mathrm{HT}_{1 \mathrm{~A}}$ antagonist, have shown significantly higher $5-\mathrm{HT}_{1 \mathrm{~A}}$ binding in MDD compared with controls across several regions (Parsey et al, 2010; Parsey et al, 2006; Sullivan et al, 2009). Also consistent with the observed sex differences in post-mortem and animal studies, differences in serotonin $1 \mathrm{~A}$ were observed across sexes. In particular, in healthy controls, women have higher $5-\mathrm{HT}_{1 \mathrm{~A}}$ binding compared with men (Parsey et al, 2002)(Jovanovic et al, 2008).

Based on this evidence, we sought to elucidate potential sex differences in the $5-\mathrm{HT}_{1 \mathrm{~A}}$ in MDD. Since they exhibit higher binding levels in control studies, we expected female depressed subjects to have higher $5-\mathrm{HT}_{1 \mathrm{~A}}$ binding than their male depressed counterparts. Probing these binding differ- ences could shed light on both the biology of MDD and, potentially, sex differences in MDD manifestation. For example, men experience higher rates of anger, aggression, and substance abuse in depression. And, it is partly because of sex differences in symptomology that for several decades, epidemiological studies reported that women were more likely than men to develop MDD (Kessler et al, 1993). (When accounting for generally different experience of depression for men and women, differences in MDD prevalence estimates between sexes are no longer observed (Martin et al, 2013).) Further, this could inform future analyses since, if sex differences in $5-\mathrm{HT}_{1 \mathrm{~A}}$ do exist, grouping males and females together for analyses (as is commonly done) could confound the search for differences between diagnostic groups, and obscure the identification of potential MDD biomarkers.

\section{MATERIALS AND METHODS}

\section{Participants}

This study was approved by the Institutional Review Boards of the New York State Psychiatric Institute and Columbia University Medical Center. Fifty subjects met DSM-IV criteria for MDD (34 female, 16 male) and fifty-seven were healthy volunteers ( 32 female, 25 male). Data from 51 of the 57 control subjects and 45 of the 50 MDD subjects have previously been reported (Miller et al, 2009; Parsey et al, 2010; Parsey et al, 2006). (A sex by diagnosis interaction was not explored or reported in the previous studies.) All participants provided a written informed consent after receiving a detailed description of the study protocol. All diagnoses were made by consensus by senior research clinicians on the basis of a structured clinical interview (SCID I) by an experienced clinician with at least a Master's degree and on other data such as past medical records. The HDRS-17, the Beck Inventory, and the Global Assessment Scale were utilized to assess depression severity and functional impairment (see Table 1). Study criteria for depressed subjects included: (1) age 18-65 years; (2) DSM IV criteria for current MDD; (3) no use of antidepressants for 4 years and absence of other psychotropic medication use for at least 2 weeks (4 weeks for neuroleptics), except benzodiazepines, which were discontinued three days prior

Table I Subject Clinical and Demographic Characteristics

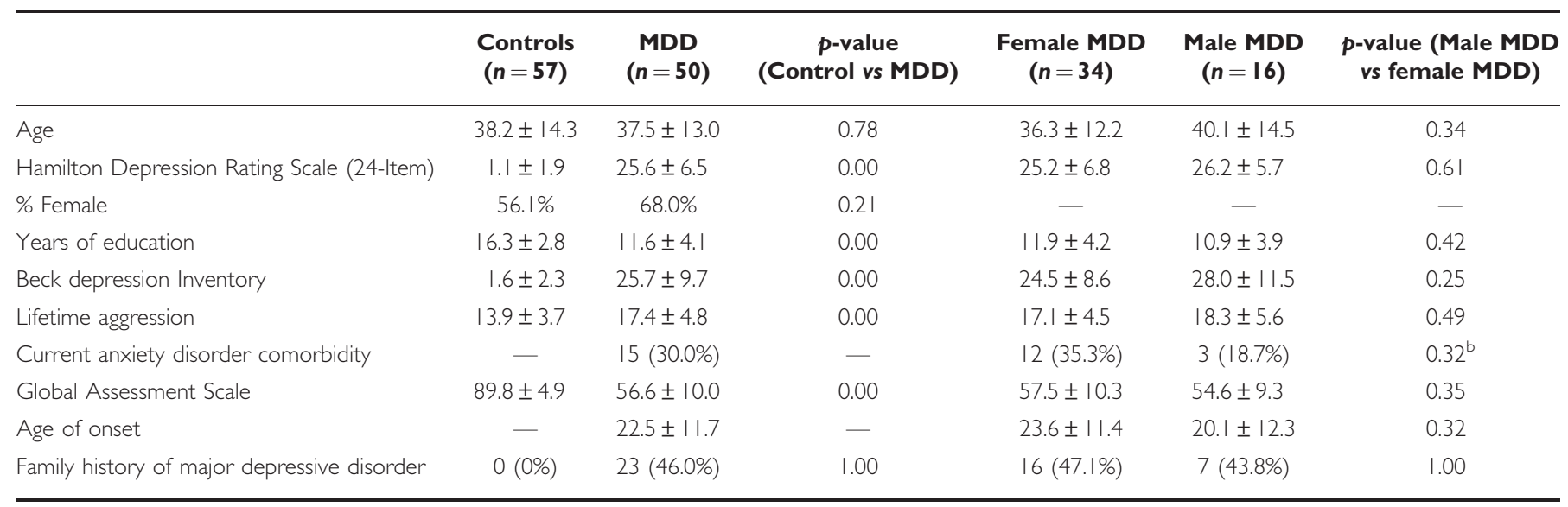


to the scan (This stringent exclusion of subjects who have been exposed to medication within the past four years is based on our previous work indicating an effect of recent medication exposure on $5-\mathrm{HT}_{1 \mathrm{~A}}$ binding (Parsey et al, 2010; Parsey et al, 2006).); (4) absence of lifetime history of alcohol or substance abuse or dependence; (5) absence of lifetime exposure to 3,4-methylenedioxymethamphetamine (MDMA, 'ecstasy'); (6) absence of significant medical conditions; (7) absence of pregnancy; (8) capacity to provide an informed consent; and (9) absence of psychosis, bipolar disorder, or schizophrenia. Screening was performed via physical exam, history, routine blood, and urine tests.

As Table 1 indicates, some of our depressed subjects were diagnosed with a current anxiety disorder (including generalized anxiety disorder, PTSD or panic disorder). We have previously shown that generalized anxiety disorder and PTSD do not affect WAY-100635 $\mathrm{BP}_{\mathrm{F}}$. However, panic disorder may be associated with reduced WAY-100635 Binding potential $\left(\mathrm{BP}_{\mathrm{F}}\right)$ (Parsey et al, 2006). For this reason, all analyses were performed including and excluding subjects with panic disorder (5 female MDD subjects).

\section{Radiochemistry and Input Function Measures}

The $\left[{ }^{11} \mathrm{C}\right]$ WAY 100635 was prepared as previously described (Parsey et al, 2010). Measurements of arterial input function, metabolites and free plasma fraction $\left(f_{p}\right)$ were also made as described previously (Parsey et al, 2010).

\section{Image Acquisition and Analysis}

Acquisitions of magnetic resonance imaging (MRI) and PET data were performed as described before (Parsey et al, 2010). Briefly, all image analysis was performed using MATLAB (The Mathworks, Natick, Massachusetts). To correct for subject motion during the PET scan, frame-byframe rigid body registration was performed to a reference frame. A mean of the motion-corrected frames was then co-registered to the MRI to generate time activity curves.

Regions of interests (ROIs) were labeled on each subject's MRI as described previously (Parsey et al, 2010) and included the ventral prefrontal cortex (VPFC), medial prefrontal cortex (MPFC), dorsolateral prefrontal cortex (DLPFC), anterior cingulate cortex (ACN), cingulate (posterior) cortex (CIN), amygdala (AMY), hippocampus (HIP), parahippocampal gyrus (PHG), insular cortex (INS), temporal cortex (TEM), parietal cortex (PAR), and occipital cortex (OCC). As the boundaries of the median and dorsal raphe nuclei (RN) are not identifiable on MRI, a $2 \mathrm{~cm}^{3}$ ellipsoid was manually placed on the raphe nuclei of each individual's mean PET image, completely encompassing the high $\left[{ }^{11} \mathrm{C}\right]$ WAY 100635 binding region of the posterior midbrain. A cylindrical ROI was drawn in the cerebellar white matter, which was used as the reference region, because, compared with cerebellar gray matter, it has lower volume of distribution $\left(\mathrm{V}_{\mathrm{T}}\right)$, comparable nonspecific binding and less-specific binding (Parsey et al, 2010).

\section{Derivation of Outcome Measures}

Regional distribution volumes of $\left[{ }^{11} \mathrm{C}\right] \mathrm{WAY} 100635$ were derived as described previously (Parsey et al, 2010). $\mathrm{BP}_{\mathrm{F}}$ is equal to the product of the available receptor density (Bavail, $\mathrm{nM}$ per $\mathrm{g}$ of tissue) and affinity (1/KD, $\mathrm{nM}$ per $\mathrm{ml}$ of brain water) (Innis et al, 2007). VT is the total regional equilibrium distribution volume. VT of the reference region $\left(\mathrm{V}_{\mathrm{ND}}\right.$, from a one tissue compartment model) was calculated and used as a constraint for the $\mathrm{K} 1 / \mathrm{k} 2$ ratio in the two tissue kinetic modeling of the ROI. $\mathrm{BP}_{\mathrm{F}}$ was calculated as $\left(\mathrm{V}_{\mathrm{T}^{-}}\right.$ $\left.\mathrm{V}_{\mathrm{ND}}\right) / \mathrm{f}_{\mathrm{P}}$ where $\mathrm{f}_{\mathrm{P}}$ is the free fraction in plasma.

Standard errors (SE) were computed for each estimated $\mathrm{BP}_{\mathrm{F}}$ value using a bootstrap algorithm that takes into account errors in metabolite, plasma and brain data (Ogden and Tarpey, 2006). For the data set used in the study, outlier data points were defined as a $\mathrm{BP}_{\mathrm{F}} \mathrm{SE}$ value of greater than $20 \mathrm{ml} / \mathrm{cm}^{3}$, that is, two standard deviations above the mean error value. Only one outlier point was detected and the Time Activity Curve (TAC) for that subject was inspected. It was observed that at the end of the TAC, after time $80 \mathrm{~min}$, a single point showed increasing activity. As this is physiologically impossible and therefore likely represents only noise, the single point was removed from the TAC and the corrected $\mathrm{BP}_{\mathrm{F}}$ and $\mathrm{BP}_{\mathrm{F}} \mathrm{SE}$ values were the values used in the analyses. Adjusting this value did not affect specificity or sensitivity calculations.

\section{Genotyping}

All subjects were genotyped for the functional $5-\mathrm{HT}_{1 \mathrm{~A}}$ gene promoter region single nucleotide polymorphism (SNP) known as 5-HT1A C(-1019)G (Huang et al, 2004; Wu and Comings, 1999).

\section{Statistics}

Regional $\mathrm{BP}_{\mathrm{F}}$ estimates were natural-log transformed before statistical modeling in order to account for heterogeneity of variances across regions. Linear mixed-effects models with SEs of transformed regional $\mathrm{BP}_{\mathrm{F}}$ estimates as weights were fit to the transformed regional $\mathrm{BP}_{\mathrm{F}}$ estimates with brain region as the fixed effect and the subject as the random effect. The dependency structure for all regions within the same subject was chosen based on Akaike Information Criterion (AIC). The final structure had a generalized compound symmetry structure allowing different variance components in different brain regions and common correlation in any two brain regions within the same subject. Fixed effects in the model included brain region, gender, diagnosis group, and the interaction between brain region and gender. Age effect was not included in the model due to previous reports citing no age dependent $5-\mathrm{HT}_{1 \mathrm{~A}}$ binding modulation in males or females (Parsey et al, 2002). Further, genotype was not included as a covariate. Although we previously reported that $5-\mathrm{HT}_{1 \mathrm{~A}} \mathrm{BP}_{\mathrm{F}}$ is associated with a stepwise increase in binding in raphe nuclei with $G$ allele frequency of the $\mathrm{C}(-1019) \mathrm{G} 5-\mathrm{HT}_{1 \mathrm{~A}}$ promoter polymorphism, that is, CC $<\mathrm{CG}<\mathrm{GG}$ (Hesselgrave and Parsey, 2013), in this expanded cohort and using weighted SE (robust measures of $\mathrm{BP}_{\mathrm{F}}$ estimate reliability (Ogden and Tarpey, 2006)), no effect of the $\mathrm{C}(-1019) \mathrm{G} 5-\mathrm{HT}_{1 \mathrm{~A}}$ promoter polymorphism effect was present. No significant genotype effect was observed in raphe binding for: controls $(p=0.19)$, $\operatorname{MDD}(p=0.62)$ and when all subjects are combined $(p=0.22)$. Similarly, no genotype effect was seen on raphe 
$\mathrm{BP}_{\mathrm{F}}$ in carriers of at least one $\mathrm{G}$ allele, that is, CC $v s \mathrm{CG} / \mathrm{GG}$ : controls $(p=0.07)$, MDD $(p=0.78)$ and when all subjects are combined $(p=0.10)$.

Another potential covariate is the number of depressive episodes. However, this is variable difficult to accurately quantify due to recall bias and difficulty identifying discrete episodes. For this reason, we did not include the number of depressive episodes in the statistical model.

No other interaction terms in first or higher order reached statistical significance level. Significance level was set at 0.05 and $p$-values were reported without multiple comparison adjustment. All tests were two-sided. Model fitting was computed using both SAS 9.2 (SAS, Cary, NC) and R 3.0.2 (R Project for Statistical Computing; www.Rproject.org).

\section{RESULTS}

\section{Effects of Sex}

Control males had a $17.8 \%$ lower $\mathrm{BP}_{\mathrm{F}}$ than control females $(\mathrm{df}=103, \quad p=0.019)$, on average, across all regions (Figure 1). Interestingly, the direction of the $\mathrm{BP}_{\mathrm{F}}$ differences between the sexes changes when examining $5-\mathrm{HT}_{1 \mathrm{~A}}$ binding in depressed subjects. In depressed subjects, males had a $14.7 \%$ higher $\mathrm{BP}_{\mathrm{F}}$ than females $(\mathrm{df}=103, p=0.15)$, on average. Male controls were therefore the group with the lowest average $\mathrm{BP}_{\mathrm{F}}$ and male depressed subjects were the group with the highest average $\mathrm{BP}_{\mathrm{F}}$.

\section{Diagnosis by Sex Interaction}

Female MDD subjects had $19.7 \%$ higher $\mathrm{BP}_{\mathrm{F}}$, on average, across all brain regions (Figure 1), compared with female controls $(\mathrm{df}=103, p=0.020)$. Male MDD subjects had
$67.0 \%$ higher $\mathrm{BP}_{\mathrm{F}}$, on average, across all regions, compared with male controls $(\mathrm{df}=103, p<0.0001)$. Post-hoc analysis assessing $\mathrm{BP}_{\mathrm{F}}$ differences between control and MDD subjects in each sex revealed a region by diagnosis interaction (Table 2).

As noted in Table 2, the greatest separation in binding between MDD and control subjects occurs in the raphe of the males ( $132 \%, p=0.000$, Figure 2$)$, therefore, we further examined this region to determine a threshold that separated male MDD and control subjects.

\section{Binding in the Raphe Nucleus}

Using leave-two-out cross-validation, thresholds for diagnostic classification were examined. Using the 25 male controls and 16 male MDD subjects, the leave-two-out approach resulted in $820\left(\left[41^{\star} 40\right] / 2\right)$ iterations. In these simulations, subjects were labeled as MDD if their raphe $\mathrm{BP}_{\mathrm{F}}$ was greater than or equal to the threshold. At each iteration, this threshold was defined as the $\mathrm{BP}_{\mathrm{F}}$ value that minimized a cost function consisting of the (negative) sum of the sensitivity and specificity, when considering all subjects except the two left out. By using this threshold, classification of the remaining two subjects was performed. The specificity and sensitivity could then be estimated from the total number of true positives/negatives and false positives/negative of the two left out subjects from every iteration. Over the 820 iterations, the average optimal threshold ranged between 30.4 and $42.2 \mathrm{ml} / \mathrm{cm}^{3}$ (average: $38.9 \mathrm{ml} / \mathrm{cm}^{3}$, standard deviation: $2.6 \mathrm{ml} / \mathrm{cm}^{3}$ ). Over all trials, the specificity was $84.8 \%$ and the sensitivity was $81.7 \%$.

Although, on average, female MDD subjects have higher binding than female controls, the separation between diagnostic groups is much smaller $(10.7 \%, p=0.078)$, resulting in considerably lower sensitivity and specificity

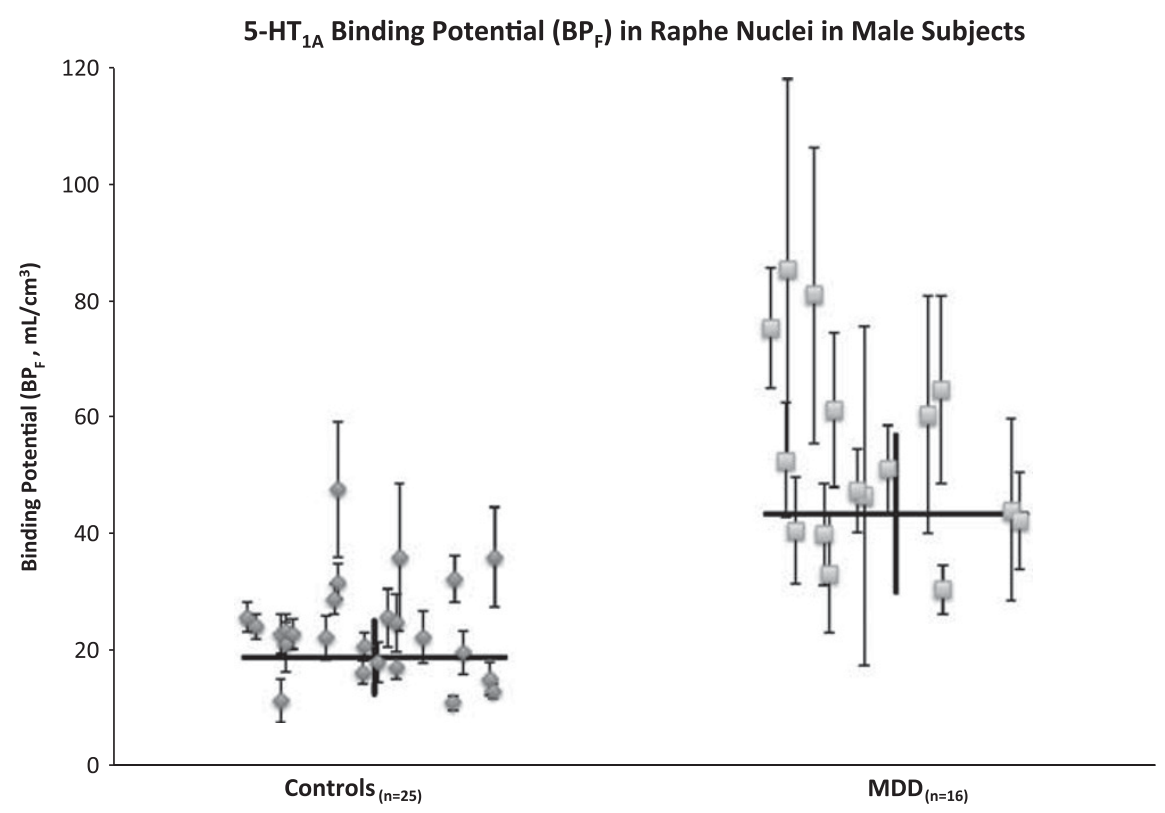

Figure I [ [ ' C]WAYI00635 binding potential $\left(\mathrm{BP}_{\mathrm{F}}\right)$ estimates for the $5-\mathrm{HT}$ IA receptor in male control and male MDD subjects in the raphe nuclei. Blue diamonds or red squares represent single measurements of raphe $\mathrm{BP}_{\mathrm{F}}$ in control and MDD subjects, respectively. Thin-capped vertical error bars represent weighted standard errors. Weighed group mean and standard error of the weighed mean of BP $\mathrm{F}$ are represented by thick horizontal lines and thick vertical lines, respectively. $\mathrm{BP}_{\mathrm{F}}$, binding potential; [ ' C]WAYI00635, N-(2-(4-(2-methoxyphenyl)-I-piperazinyl)ethyl)-N-(2-pyridinyl)cyclo-hexanecarboxamide; 5-HT IA, serotonin-IA receptor. 
in distinguishing MDD in females (sensitivity $=76.3 \%$, specificity $=62.5 \%, 2145$ iterations, threshold range: $32.0-$ $34.9 \mathrm{ml} / \mathrm{cm}^{3}$ ).

Excluding the subjects with comorbid panic disorder did not significantly affect any of the reported results.

\section{DISCUSSION}

\section{Elevated $\left[{ }^{11} \mathrm{C}\right] \mathrm{WAY} 100635 \mathrm{BP}_{\mathrm{F}}$ in Depression}

As revealed in Figure 2, regardless of the interaction with sex, elevated $\left[{ }^{11} \mathrm{C}\right]$ WAY100635 was observed in MDD.

Table 2 Average Percent Difference in $\mathrm{BP}_{\mathrm{F}}$ Between Controls and Subjects with Major Depressive Disorder

\begin{tabular}{lcc}
\hline & Male (\%) & Female (\%) \\
\hline Raphe nucleus & 132.59 & 10.68 \\
Amygdala & 64.07 & 25.03 \\
Hippocampus & 74.22 & 19.59 \\
Parahippocampal gyrus & 87.96 & 34.76 \\
Temporal lobe & 87.07 & 27.23 \\
Anterior cingulate & 80.47 & 30.75 \\
Cingulate & 80.79 & 26.65 \\
Dorsolateral prefrontal cortex & 83.69 & 31.10 \\
Medial prefrontal cortex & 84.79 & 31.13 \\
Ventral prefrontal cortex & 84.94 & 28.59 \\
Insula & 76.78 & 22.48 \\
Occipital lobe & 95.18 & 20.50 \\
Parietal lobe & 98.55 & 23.82 \\
\hline
\end{tabular}

(In all cases, average $\mathrm{BP}_{\mathrm{F}}$ was greater in MDD subjects than controls).
Although our laboratory has consistently reported a significantly higher $\mathrm{BP}_{\mathrm{F}}$ in $\mathrm{MDD}$ subjects, as compared with healthy controls (Parsey et al, 2006), there are a number of previously published 5- $\mathrm{HT}_{1 \mathrm{~A}}$ PET studies that reported reduced binding in MDD (Bhagwagar et al, 2004; Sargent et al, 2000). However, a 2010 paper reconciled these differences (Parsey et al, 2010) by clarifying that (1) depressed individuals exposed to antidepressant medications exhibit higher binding. (The effect of psychiatric medications on neurochemistry has long been considered a possible confounding variable in neurotransmitter receptor studies.) (2) Choice of reference region and outcome measure $\left(\mathrm{BP}_{\mathrm{F}}\right.$ vs $\left.\mathrm{BP}_{\mathrm{ND}}\right)$ greatly affects outcome. Briefly, $\mathrm{BP}_{\mathrm{ND}}$ is the ratio of binding in the region of interest to that of a reference region. Although an ideal reference region has no specific binding, like most tracers, reference regions used for $\left[{ }^{11} \mathrm{C}\right]$ WAY100635 do contain a low density of 5-HT $\mathrm{T}_{1 \mathrm{~A}}$ receptors. An added complexity is that, using this tracer, the specific and nonspecific binding in the reference region are of similar magnitude. Therefore, depressed subjects, who exhibit higher $5-\mathrm{HT}_{1 \mathrm{~A}}$, expression will have a non-negligible increase in the denominator of the $\mathrm{BP}_{\mathrm{ND}}$ measure, resulting in the MDD cohort appearing to have lower binding than controls. This is summarized in a recent review (Hesselgrave and Parsey, 2013) and serves as a reminder of the dramatic effects choice of outcome measure may have in PET studies.) This debate was ultimately resolved when the observed elevated $\mathrm{BP}_{\mathrm{F}}$ in MDD, by using samples of depressed subjects who had been off medication for at least 4 years, were duplicated and then triplicated (Miller et al, 2013; Parsey et al, 2010).

\section{Sex Differences in $5-\mathrm{HT}_{1 \mathrm{~A}}$}

In this work, it was observed that $5-\mathrm{HT}_{1 \mathrm{~A}}$ binding differences between depressed and control subjects varied

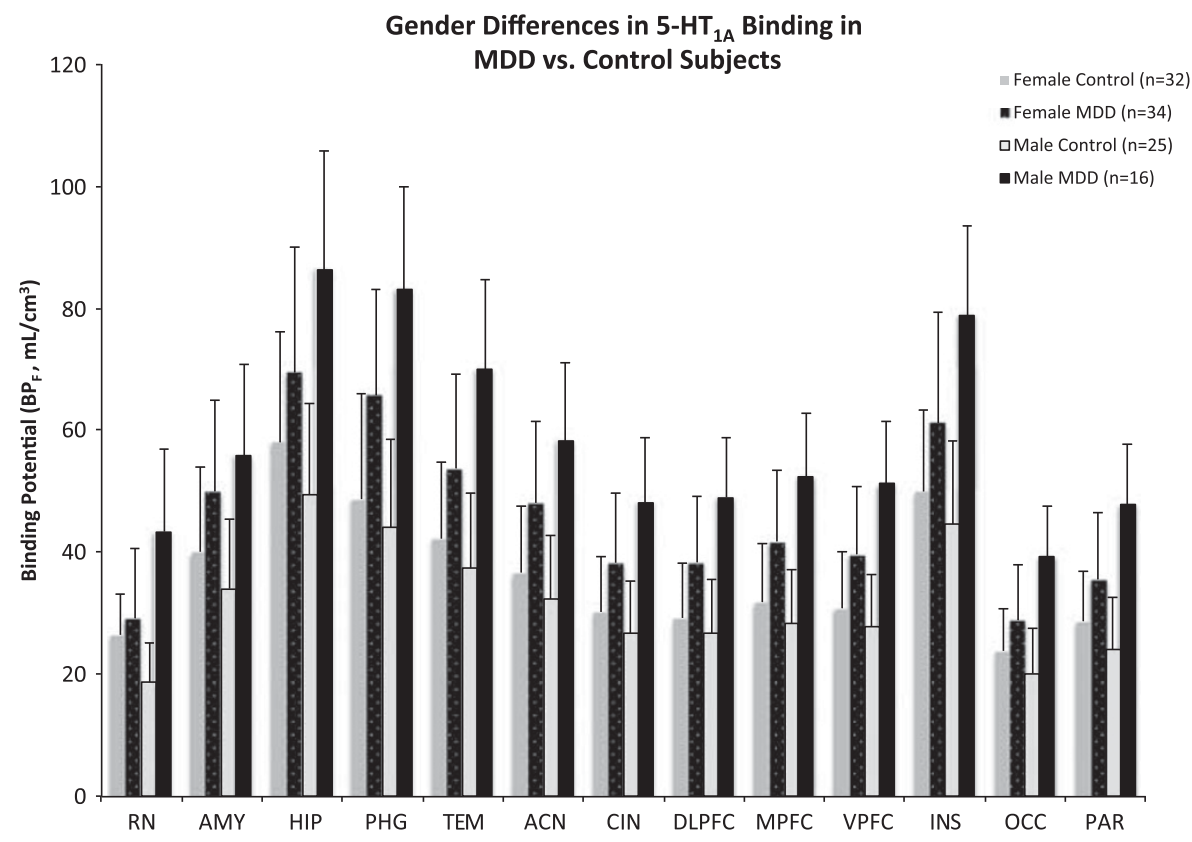

Figure 2 [ I C]WAYI00635 binding potential $\left(\mathrm{BP}_{\mathrm{F}}\right)$ estimates for the 5-HTIA receptor in male control and male MDD subjects across 13 regions of interest. Thin-capped vertical bars represent weighted standard errors. Raphe nuclei (RN), ventral prefrontal cortex (VPFC), medial prefrontal cortex (MPFC), dorsolateral prefrontal cortex (DLPFC), anterior cingulate cortex (ACN), cingulate (posterior) cortex (CIN), amygdala (AMY), hippocampus (HIP), parahippocampal gyrus (PHG), insular cortex (INS), temporal cortex (TEM), parietal cortex (PAR), and occipital cortex (OCC). 
by sex. The role of serotonin in depression and, in particular, the relationship between raphe 5-HT $1 \mathrm{~A}$ and $\mathrm{MDD}$ (Kishi et al, 2013; Miller et al, 2009; Miller et al, 2013; Parsey et al, 2010; Parsey et al, 2006), suggests that differences in MDD pathophysiology between the sexes may be because of sex hormones and their modulation of the $5-\mathrm{HT}_{1 \mathrm{~A}}$ receptor. This is confirmed by both animal and human studies (though the majority of animal studies examining the involvement of $5-\mathrm{HT}_{1 \mathrm{~A}}$ in $\mathrm{MDD}$ have used males only or samples with a disproportionate ratio of male to female subjects (Castro et al, 2003; Le Poul et al, 2000; Nishi et al, 2009)).

To date, few studies have looked at the role of sex in the modulation of $5-\mathrm{HT}_{1 \mathrm{~A}}$ specifically in the pathophysiology of MDD. Therefore, our initial hypothesis assumed that, matching the controls, the female $5-\mathrm{HT}_{1 \mathrm{~A}}$ binding would be higher than the males in the depressed subjects. However, a 2010 examining alpha-[(11)C]MTrp brain trapping, an index of serotonin synthesis showed that serotonergic differences exist in both healthy individuals and those with MDD across sexes (Frey et al, 2010). Sex differences in serotonin synthesis were seen in multiple regions of the prefrontal cortex and limbic system, which are involved in mood regulation. Another study looking into the sex differences within the serotonergic system showed that although healthy females exhibit lower cortical trapping of alpha-[(11)C]MTrp than healthy males, females with MDD exhibit higher alpha-[(11)C]MTrp than males with MDD (Frey et al, 2010; Sakai et al, 2006). This trend is consistent with the findings of the current study, namely that healthy females exhibit higher $5-\mathrm{HT}_{1 \mathrm{~A}}$ binding than healthy males, females with $\mathrm{MDD}$ exhibit lower $5-\mathrm{HT}_{1 \mathrm{~A}}$ binding than males with MDD.

\section{5-HT ${ }_{1 \mathrm{~A}} \mathrm{BP}_{\mathrm{F}}$ in the Raphe as a Biomarker for MDD}

A biomarker or endophenotype of MDD could significantly advance our understanding and treatment of this psychopathology in several ways. As pointed out by Peterson et al (Peterson and Weissman, 2011), a biomarker for MDD could aid: in classifying the heterogeneity observed across MDD presentation into identifiable sub-diagnostic categories and therefore allow more customized treatment strategies; the search for genetic and environmental factors; in identifying those likely to have a chronic course, be treatment resistant, or respond to medication vs therapy; and in identifying those at increased risk for MDD. The last possibility is especially important since MDD is only 31$42 \%$ genetically determined.(Sullivan et al, 2000) For this reason, clinicians cannot accurately predict who will develop the illness based on family history alone. Being able to quantify their risk of developing MDD, would allow for preventative strategies to be taken to improve their future mental health outcomes..

This study found that using a threshold value to categorize subjects as either MDD or control based solely on raphe $5-\mathrm{HT}_{1 \mathrm{~A}} \mathrm{BP}_{\mathrm{F}}$ values yielded extremely high diagnostic sensitivity and specificity ( 81.7 and $84.8 \%$, respectively). In previous work, we have shown that $5-\mathrm{HT}_{1 \mathrm{~A}}$ binding remains elevated in the remitted depressed. This suggests that the increased binding is a trait marker of depression. (Further, such a marker may be effective for bipolar depression as well. We have previously observed higher $5-\mathrm{HT}_{1 \mathrm{~A}} \mathrm{BP}_{\mathrm{F}}$ in bipolar disorder (Sullivan et al, 2009). Moreover, post-hoc analysis in the bipolar disorder study reported that among the male subjects, both the main effect of diagnosis and the region by diagnosis interaction terms were statistically significant. In contrast however, the $5-\mathrm{HT}_{1 \mathrm{~A}} \mathrm{BP}_{\mathrm{F}}$ in female control subjects did not differ from the female bipolar subjects nor was the interaction term significant. This is consistent with the trend observed in the current study.)

However, one constraint on the practicality of PET in clinical psychiatry is the invasiveness and cost of the procedure. An ideal alternative would be the development of a blood-based biomarker, such as tracer free fraction or platelet $5-\mathrm{HT}_{1 \mathrm{~A}}$ levels. The free fraction $\left(\mathrm{f}_{\mathrm{P}}\right)$ of a PET tracer can be measured from a single venous sample (Milak et al, 2010) and is currently used in the calculation of $\mathrm{BP}_{\mathrm{F}}$. In this study, however, we found that $\left[{ }^{11} \mathrm{C}\right] \mathrm{WAY} 100635 \mathrm{f}_{\mathrm{P}}$ values achieve much lower sensitivity and specificity than $\mathrm{BP}_{\mathrm{F}}$ in the raphe (sensitivity/specificity: $80.9 \% / 60.2 \%, 48.6 \% /$ $57.1 \%, 56.3 \% / 59.5 \%$ for males, females, and a combined group, respectively, by using the sensitivity analysis described in the methods, data not shown). A 2014 study reported that platelet $5-\mathrm{HT}_{1 \mathrm{~A}}$ levels significantly differ between control and MDD subjects using western blot analysis (Zhang et al, 2014). However, although promising, this study failed to report diagnostic measures such as sensitivity and specificity. Although technological advances may improve the accuracy of these markers, the first step to uncovering useful surrogate markers is to establish the measure (such as $5-\mathrm{HT}_{1 \mathrm{~A}}$ binding in the raphe) for which a surrogate is needed.

\section{Limitations}

This pilot study involved 50 (34 female, 16 male) MDD and 57 (32 female, 25 male) control individuals. Although the results of this study are promising, the findings must be replicated in a larger cohort. Further, as described above, there is a probable connection between female sex hormones and regulation of mood. Consequently, future studies that measure 5- $\mathrm{HT}_{1 \mathrm{~A}}$ binding in females should adjust for covariates such as phase of menstrual cycle. By using venous sampling, fluctuations in estrogen, and progesterone, levels that occur during the menstrual cycle can be taken in account to more accurately calculate measures of $5-\mathrm{HT}_{1 \mathrm{~A}}$ binding. Using this information could help achieve higher sensitivity/ specificity in female cohorts in the future.

\section{CONCLUSION}

There are currently no biomarkers of MDD that are used clinically. In this study, we show that serotonin $1 \mathrm{~A}$ binding $\left(\mathrm{BP}_{\mathrm{F}}\right)$ in the raphe, a small region in the midbrain from which most serotonergic neurons originate, reveals a diagnostic threshold that can distinguish male depressed and control subjects with high specificity and sensitivity. As such, this method may offer an objective biomarker of depression in males. Identification of such a biomarker would offer insight into MDD pathophysiology, providing direction for future development and discovery of nonimaging-based biomarkers (for both sexes). These objective 
measures would reduce the burden of MDD, by potentially allowing for improved diagnosis, earlier identification of failed treatment, and early intervention.

\section{FUNDING AND DISCLOSURE}

Dr Miller's family owns stock in Johnson \& Johnson, unrelated to the current manuscript. Dr. Sullivan had previously consulted for, and, as of 6/3/2014, began fulltime work for Tonix Pharmaceuticals, all work unrelated to the present study. Dr Oquendo receives royalties for the use of the Columbia Suicide Severity Rating Scale and received financial compensation from Pfizer for the safety evaluation of a clinical facility, unrelated to the current manuscript. She was the recipient of a grant from Eli Lilly to support a year's salary for the Lilly Suicide Scholar, Enrique BacaGarcia, MD, PhD. She has received unrestricted educational grants and/or lecture fees from Astra-Zeneca, Bristol Myers Squibb, Eli Lilly, Janssen, Otsuko, Pfizer, Sanofi-Aventis, and Shire. Her family owns stock in Bristol Myers Squibb. Dr. Mann receives royalties for commercial use of the CSSRS from the Research Foundation for Mental Hygiene and has stock options in Qualitas Health, a start up company making omega-3-fatty-acid products.

\section{ACKNOWLEDGEMENTS}

We acknowledge the biostatistical support from Ruofeng Wen and the Biostatistical Consulting Core at School of Medicine, Stony Brook University. The work was supported by the following grants: R01MH40695 (PI: Mann), P50MH062185 (PI: Mann), R01MH074813 (PI: Parsey), R01MH090276 (PI: Parsey), and K01MH091354 (PI: DeLorenzo) awarded by the National Institutes of Health, a Clinical and Translational Science Award (CTSA) from Columbia University, and grants from the American Foundation for the Prevention of Suicide (AFSP) and the National Alliance for Research on Schizophrenia and Depression (NARSAD).

\section{REFERENCES}

Arango V, Underwood MD, Boldrini M, Tamir H, Kassir SA, Hsiung S et al (2001). Serotonin 1A receptors, serotonin transporter binding and serotonin transporter mRNA expression in the brainstem of depressed suicide victims. Neuropsychopharmacology 25: 892-903.

Bhagwagar Z, Rabiner EA, Sargent PA, Grasby PM, Cowen PJ (2004). Persistent reduction in brain serotonin1A receptor binding in recovered depressed men measured by positron emission tomography with [11C]WAY-100635. Mol Psychiatry 9: 386-392.

Birzniece V, Johansson IM, Wang MD, Seckl JR, Backstrom T, Olsson T (2001). Serotonin 5-HT(1A) receptor mRNA expression in dorsal hippocampus and raphe nuclei after gonadal hormone manipulation in female rats. Neuroendocrinology 74: 135-142.

Blier P, Pineyro G, el Mansari M, Bergeron R, de Montigny C (1998). Role of somatodendritic 5-HT autoreceptors in modulating 5-HT neurotransmission. Ann N Y Acad Sci 861: 204-216.

Boldrini M, Underwood MD, Mann JJ, Arango V (2008). Serotonin$1 \mathrm{~A}$ autoreceptor binding in the dorsal raphe nucleus of depressed suicides. J Psychiatr Res 42: 433-442.
Castro M, Diaz A, del Olmo E, Pazos A (2003). Chronic fluoxetine induces opposite changes in $G$ protein coupling at pre and postsynaptic 5-HT1A receptors in rat brain. Neuropharmacology 44: 93-101.

Flugge G, Pfender D, Rudolph S, Jarry H, Fuchs E (1999). 5HT1Areceptor binding in the brain of cyclic and ovariectomized female rats. J Neuroendocrinol 11: 243-249.

Frankfurt M, McKittrick CR, Mendelson SD, McEwen BS (1994). Effect of 5,7-dihydroxytryptamine, ovariectomy and gonadal steroids on serotonin receptor binding in rat brain. Neuroendocrinology 59: 245-250.

Frey BN, Skelin I, Sakai Y, Nishikawa M, Diksic M (2010). Gender differences in alpha-[(11)C]MTrp brain trapping, an index of serotonin synthesis, in medication-free individuals with major depressive disorder: a positron emission tomography study. Psychiatry Res 183: 157-166.

Gottfries CG, Roos BE, Winblad B (1974). Determination of 5hydroxytryptamine, 5-hydroxyindoleacetic acid and homovanillic acid in brain tissue from an autopsy material. Acta Psychiatr Scand 50: 496-507.

Hesselgrave N, Parsey RV (2013). Imaging the serotonin 1A receptor using [11C]WAY100635 in healthy controls and major depression. Philos Trans R Soc Lond B Biol Sci 368: 20120004.

Hierholzer R (2006). Remission rates for depression in $S_{T A R}{ }^{\star} D$ study. Am J Psychiatry 163: 1293; author reply 1293-1294.

Huang YY, Battistuzzi C, Oquendo MA, Harkavy-Friedman J, Greenhill L, Zalsman G et al (2004). Human 5-HT1A receptor C(-1019)G polymorphism and psychopathology. Int J Neuropsychopharmacol 7: 441-451.

Innis RB, Cunningham VJ, Delforge J, Fujita M, Gjedde A, Gunn RN et al (2007). Consensus nomenclature for in vivo imaging of reversibly binding radioligands. J Cereb Blood Flow Metab 27: 1533-1539.

Insel TR (2009). Disruptive insights in psychiatry: transforming a clinical discipline. J Clin Invest 119: 700-705.

Jovanovic H, Lundberg J, Karlsson P, Cerin A, Saijo T, Varrone A et al (2008). Sex differences in the serotonin $1 \mathrm{~A}$ receptor and serotonin transporter binding in the human brain measured by PET. NeuroImage 39: 1408-1419.

Kessler RC, Berglund P, Demler O, Jin R, Koretz D, Merikangas KR et al (2003). The epidemiology of major depressive disorder: results from the National Comorbidity Survey Replication (NCS-R). JAMA 289: 3095-3105.

Kessler RC, McGonagle KA, Swartz M, Blazer DG, Nelson CB (1993). Sex and depression in the National Comorbidity Survey. I: Lifetime prevalence, chronicity and recurrence. J Affect Disord 29: 85-96.

Kishi T, Yoshimura R, Fukuo Y, Okochi T, Matsunaga S, UmeneNakano W et al (2013). The serotonin 1A receptor gene confer susceptibility to mood disorders: results from an extended metaanalysis of patients with major depression and bipolar disorder. Eur Arch Psychiatry Clin Neurosci 263: 105-118.

Le Poul E, Boni C, Hanoun N, Laporte AM, Laaris N, Chauveau J et al (2000). Differential adaptation of brain 5-HT1A and 5HT1B receptors and 5-HT transporter in rats treated chronically with fluoxetine. Neuropharmacology 39: 110-122.

Martin LA, Neighbors HW, Griffith DM (2013). The experience of symptoms of depression in men vs women: analysis of the National Comorbidity Survey Replication. JAMA Psychiatry 70: 1100-1106.

Maswood S, Stewart G, Uphouse L (1995). Gender and oestrus cycle effects of the 5-HT1A agonist 8-OH-DPAT on hypothalamic serotonin. Pharmacol Biochem Behav 51: 807-813.

Merikangas KR, Akiskal HS, Angst J, Greenberg PE, Hirschfeld RM, Petukhova $\mathrm{M}$ et al (2007). Lifetime and 12-month prevalence of bipolar spectrum disorder in the National Comorbidity Survey replication. Arch Gen Psychiatry 64: 543-552.

Milak MS, DeLorenzo C, Zanderigo F, Prabhakaran J, Kumar JS, Majo VJ et al (2010). In vivo quantification of human serotonin 
1A receptor using 11C-CUMI-101, an agonist PET radiotracer. J Nucl Med 51: 1892-1900.

Miller JM, Brennan KG, Ogden TR, Oquendo MA, Sullivan GM, Mann JJ et al (2009). Elevated serotonin 1A binding in remitted major depressive disorder: evidence for a trait biological abnormality. Neuropsychopharmacology 34: 2275-2284.

Miller JM, Hesselgrave N, Ogden RT, Zanderigo F, Oquendo MA, Mann JJ et al (2013). Brain serotonin 1A receptor binding as a predictor of treatment outcome in major depressive disorder. Biol Psychiatry 74: 760-767.

Nishi K, Kanemaru K, Diksic M (2009). A genetic rat model of depression, Flinders sensitive line, has a lower density of 5-HT(1A) receptors, but a higher density of 5- $\mathrm{HT}(1 \mathrm{~B})$ receptors, compared to control rats. Neurochem Int 54: 299-307.

Nishizawa S, Benkelfat C, Young SN, Leyton M, Mzengeza S, de Montigny C et al (1997). Differences between males and females in rates of serotonin synthesis in human brain. Proc Natl Acad Sci USA 94: 5308-5313.

Ogden RT, Tarpey T (2006). Estimation in regression models with externally estimated parameters. Biostatistics 7: 115-129.

Palucha A, Pilc A (2007). Metabotropic glutamate receptor ligands as possible anxiolytic and antidepressant drugs. Pharmacol Ther 115: $116-147$.

Parsey RV, Ogden RT, Miller JM, Tin A, Hesselgrave N, Goldstein E et al (2010). Higher serotonin $1 \mathrm{~A}$ binding in a second major depression cohort: modeling and reference region considerations. Biol Psychiatry 68: 170-178.

Parsey RV, Oquendo MA, Ogden RT, Olvet DM, Simpson N, Huang YY et al (2006). Altered serotonin 1A binding in major depression: a [carbonyl-C-11]WAY100635 positron emission tomography study. Biol Psychiatry 59: 106-113.

Parsey RV, Oquendo MA, Simpson NR, Ogden RT, Van Heertum R, Arango $\mathrm{V}$ et al (2002). Effects of sex, age, and aggressive traits in man on brain serotonin 5-HT1A receptor binding potential measured by PET using [C-11]WAY-100635. Brain Res 954: 173-182.

Pecins-Thompson M, Bethea CL (1999). Ovarian steroid regulation of serotonin-1A autoreceptor messenger RNA expression in the dorsal raphe of rhesus macaques. Neuroscience 89: 267-277.

Peterson BS, Weissman MM (2011). A brain-based endophenotype for major depressive disorder. Annu Rev Med 62: 461-474.

Robichaud M, Debonnel G (2005). Oestrogen and testosterone modulate the firing activity of dorsal raphe nucleus serotonergic neurones in both male and female rats. J Neuroendocrinol 17: 179-185.
Rosecrans JA (1970). Differences in brain area 5-hydroxytryptamine turnover and rearing behavior in rats and mice of both sexes. Eur J Pharmacol 9: 379-382.

Sakai Y, Nishikawa M, Leyton M, Benkelfat C, Young SN, Diksic M (2006). Cortical trapping of alpha-[(11)C]methyl-l-tryptophan, an index of serotonin synthesis, is lower in females than males. NeuroImage 33: 815-824.

Sargent PA, Kjaer KH, Bench CJ, Rabiner EA, Messa C, Meyer J et al (2000). Brain serotonin1A receptor binding measured by positron emission tomography with [11C]WAY-100635: effects of depression and antidepressant treatment. Arch Gen Psychiatry 57: $174-180$.

Savitz J, Lucki I, Drevets WC (2009). 5-HT(1A) receptor function in major depressive disorder. Prog Neurobiol 88: 17-31.

Savitz JB, Drevets WC (2013). Neuroreceptor imaging in depression. Neurobiol Dis 52: 49-65.

Singh I, Rose N (2009). Biomarkers in psychiatry. Nature 460: 202-207.

Stockmeier CA (2003). Involvement of serotonin in depression: evidence from postmortem and imaging studies of serotonin receptors and the serotonin transporter. J Psychiatric Res 37: 357-373.

Sullivan GM, Ogden RT, Oquendo MA, Kumar JS, Simpson N, Huang YY et al (2009). Positron emission tomography quantification of serotonin-1A receptor binding in medicationfree bipolar depression. Biol Psychiatry 66: 223-230.

Sullivan PF, Neale MC, Kendler KS (2000). Genetic epidemiology of major depression: review and meta-analysis. Am J Psychiatry 157: $1552-1562$

World Health Orangization (2004). Global Burden of Disease 2004 Update.

World Health Organization, Beaglehole R, Irwin A, Prentice T (2004). Annex Table 3: Burden of disease in DALYs by cause, sex, and mortality stratum in WHO regions, estimates for 2002 . The world health report 2004: changing history. World Health Organization: Geneva, Vol xvii, $169 \mathrm{p}$.

Wu S, Comings DE (1999). A common C-1018G polymorphism in the human 5-HT1A receptor gene. Psychiatr Genet 9: 105-106.

Zhang L, Ma W, Barker JL, Rubinow DR (1999). Sex differences in expression of serotonin receptors (subtypes $1 \mathrm{~A}$ and $2 \mathrm{~A}$ ) in rat brain: a possible role of testosterone. Neuroscience 94: 251-259.

Zhang ZJ, Wang D, Man SC, Ng R, McAlonan GM, Wong HK et al (2014). Platelet 5-HT receptor correlates with major depressive disorder in drug-free patients. Prog Neuropsychopharmacol Biol Psychiatry 53C: 74-79. 